\title{
Study on the preparation and formation mechanism of barium sulphate nanoparticles modified by different organic acids
}

\author{
YUHUA SHEN, CHUANHAO LI, XUEMEI ZHU, ANJIAN XIE, * LINGGUANG QIU and \\ JINMIAO ZHU \\ Department of Chemistry and Chemical Engineering, Anhui University, Hefei 230 039, P.R. China \\ e-mail: anjx@163.com
}

MS received 9 February 2007; revised 15 May 2007

\begin{abstract}
This paper reports a simple method to prepare barium sulphate nanoparticles by use of tetradecanoic acid, hexadecanoic acid and stearic acid as modifier. The barium sulphate nanoparticles obtained are characterized by using Fourier transform infra-red spectroscopy (FT-IR), powder X-ray diffraction (XRD), transmission electron microscopy (TEM), dynamic laser light scatter (DLLS) and thermogravimetric analysis (TGA), respectively. The results show that the $\mathrm{BaSO}_{4}$ particles are all spherical and in the nano-scale. Our method has a better dispersion and controllable diameter dependent on the length of the chain of organic acid and the $\mathrm{pH}$ value of the system. A possible mechanism is also discussed.
\end{abstract}

Keywords. Barium sulphate; organic acid; nanoparticles.

\section{Introduction}

Due to the unique properties and applications materials made of particles with diameter less than $100 \mathrm{~nm}$ have attracted a great deal of attention. ${ }^{1}$ However, nanoparticles are prone to aggregate because of the high surface area-to-volume ratio, which would impede their application. Organo-modification was one of the methods employed to stabilize such ultrafine particles. The advantage of this method is that the organo layer could not only prevent particles from aggregating, but also result in a stable dispersion in organic solvents.

$\mathrm{BaSO}_{4}$ nanoparticles were widely used as additives in painting to improve the polish. In paper making, the addition of $\mathrm{BaSO}_{4}$ nanoparticles would make smoother and the paper obtained would have some novel properties, for instance, radiation protection. In other fields, such as cosmetics, ceramics, pigments, and off shore oil, ${ }^{2,3}$ the performance of the products could be promoted by adding $\mathrm{BaSO}_{4}$ nanoparticles. And often the products were endowed with some novel properties.

Recently, a great deal of attention has been placed on the mass production of $\mathrm{BaSO}_{4}$ nanoparticles. Due to its tendency of aggregation and the fact that the

\footnotetext{
*For correspondence
}

physical and chemical properties of $\mathrm{BaSO}_{4}$ nanoparticles were determined by size and shape, ${ }^{4}$ it was significant to find the most appropriate method to prepare $\mathrm{BaSO}_{4}$ nanoparticles with controlled size and morphology.

Many different approaches have been reported for preparation of $\mathrm{BaSO}_{4}$ nanoparticles including the addition of different additives, ${ }^{5-8}$ induction by LB monolayer $^{9}$ and microemulsion. ${ }^{10-12}$ The addition of additives and induction by LB monolayer could cause a significant change in morphology, but the size was generally in the micron scale rather than nanometer scale. The size and corresponding morphology obtained in W/O microemulsions or reverse micelle approach could be controlled well by adjusting the molar ratio of water to surfactant. However, the product yield was rather low because of the poor solubility of salts in conventional microemulsions. There were also some reports about preparation of organo-modified $\mathrm{BaSO}_{4},{ }^{13}$ but the $\mathrm{BaSO}_{4}$ obtained was in micron scale. Although preparation of organocapped $\mathrm{BaSO}_{4}$ was earlier described, ${ }^{14}$ the condition was not suited to the industry.

In order to meet industrial demands, we propose a simple method to prepare $\mathrm{BaSO}_{4}$ nanoparticles using organic acid as modifier. The results were successful. It is hoped this study will benefit increased application of $\mathrm{BaSO}_{4}$. 


\section{Experimental section}

\subsection{Chemicals}

Tetradecanoic acid, hexadecanoic acid, stearic acid, anhydrous sodium sulphate, dihydrate barium chloride, ammonia and ethanol (all of AR grade) were supplied by Beijing Chemicals. Ultrapure water produced by milli RO-milli Q system was used throughout.

\subsection{Sample preparation}

Solution A: $\mathrm{Na}_{2} \mathrm{SO}_{4}(0 \cdot 1 \mathrm{M})$-ethanol-water solution $\left(V_{\text {ethanol }}: V_{\text {water }}=1: 1\right), 25 \mathrm{ml}$; Solution B: $\mathrm{BaCl}_{2}(0 \cdot 1 \mathrm{M})$ ethanol-water solution $\left(V_{\text {ethanol }}: V_{\text {water }}=1: 1\right), 25 \mathrm{ml}$, containing tetradecanoic acid, hexadecanoic acid and stearic acid, respectively.

Three different approaches as shown below were used in this study:

Approach (I ): Solution A was directly dropped into B.

Approach (II): The $\mathrm{pH}$ of solution $\mathrm{B}$ was adjusted to 8-9. Solution A was then added in drops into B.

Approach (III): The conditions were the same as in (II) except that the $\mathrm{pH}$ of solution A was adjusted to $8-9$. The $\mathrm{pH}$ of the above solutions was adjusted using ammonia solution. After stirring, the solutions were kept $30 \mathrm{~min}$ for allowing the precipitate to settle. Precipitate were then separated, centrifugalized and rinsed with doubly distilled water and pure alcohol, then dried in infrared dryer.

\subsection{Characterization}

Infrared spectroscopy on $\mathrm{KBr}$ pellets was recorded on a Nicolet NEXUS 870 fourier transform infra-red spectrophotometer. X-ray powder diffraction (XRD) was performed on a DX-2000 X-ray diffractometer under $\mathrm{CuK} \alpha$ radiation $(\lambda=1.5418 \AA)$, the operation voltage and current at $35 \mathrm{kV}$ and $20 \mathrm{~mA}$, and the $2 \theta$ range from 4 to $80^{\circ}$ in steps of $0.03^{\circ}$ with a count time of $2 \mathrm{~s}$. The size and morphology of $\mathrm{BaSO}_{4}$ obtained were determined by JEM-1200 EX transmission electronic microscopy and the size distribution was measured by DLLS on the Zetasizer $3000 \mathrm{HS}_{\mathrm{A}}$. Thermogravimetric analysis was obtained using Perkin-Elmer pyrir-1 TGA instrument under nitrogen at the heating rate of $10 \mathrm{k} \mathrm{min}^{-1}$.

\section{Results and discussion}

In order to determine the optimal addition of organic acid, different experiments were performed and the results are shown in figure 1.

Initial experiments were done using approach (I) to choose the most appropriate amount of the stearic acid. Figure $1(\mathrm{a}-\mathrm{d})$ showed that the size of the particle could be controlled within a certain range by adjusting the addition of the stearic acid and that the average diameters could be estimated at 293, 115, 92 and $177 \mathrm{~nm}$, respectively. The corresponding standard deviation of particle size was 52.9, 19.3, 17.0 and $13 \cdot 1$, based on the formula of standard deviation:

$$
\mathrm{SD}=\sqrt{\sum_{i=1}^{n}\left(x_{i}-\bar{x}\right)^{2} /(n-1)},
$$

where $x_{i}$ is the diameter of the particle and $\bar{x}$ the average diameter. Considering average diameter and standard deviation, the most appropriate amount of the stearic was estimated to $3 \mathrm{wt} \%$ of the theoretical yield of $\mathrm{BaSO}_{4}$.

Subsequently, the effect of the additive method of the ammonia solution on the particle size was investigated (figure 1e-f) using approaches (II) and (III). In the two experiments, the addition of stearic acid was $3 \mathrm{wt} \%$ which agrees with previous results. Figure $1 \mathrm{e}-\mathrm{f}$ show that the particles size obtained by approach (III) (about $22 \pm 2.9 \mathrm{~nm}$ ) was much smaller than that by approach (II) (about $106 \pm 10 \cdot 1 \mathrm{~nm}$ ). The results showed that approach (III) was more suitable for preparation of smaller $\mathrm{BaSO}_{4}$ particles.

Experiments to determine the optimal addition of tetradecanoic acid and hexadecanoic acid were carried out using approach (III) and the best dosage was estimated to be $6 \%$ and $4 \%$ respectively (figure $1 \mathrm{~g}-\mathrm{h}$ ). It could be seen from figure $1(\mathrm{f}-\mathrm{h})$ that the average diameters decreased with the difference of the organic acid, which were $49 \pm 8.0 \mathrm{~nm}, 31 \pm 6.1 \mathrm{~nm}$ and $22 \pm 2.9 \mathrm{~nm}$ respectively.

TEM images of different approaches (figure 2) indicate that the particles were all spherical. Figure $2 \mathrm{a}$ is the TEM images of the particles obtained in the absence of organic acid, whose average diameter was about $80 \pm 2.3 \mathrm{~nm}$ based on 50 particles (the results below were based on the same number of particles). But the aggregation is obvious. Based on approach (I), the average diameter was about $70 \pm$ $3.0 \mathrm{~nm}$ as shown in figure $2 \mathrm{~b}$. Although the diameter is smaller than that in figure $2 a$, the aggregation 


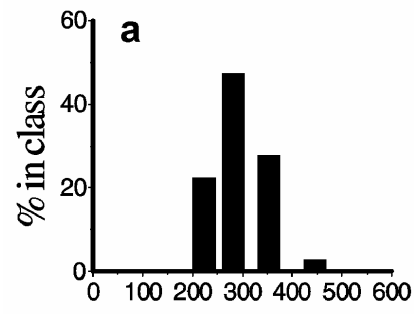

Diameter $(\mathrm{nm})$

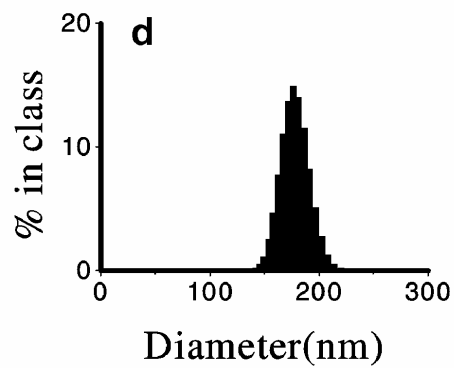

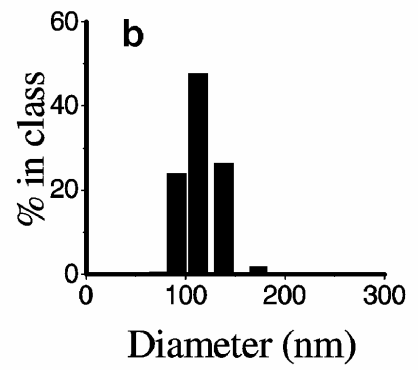

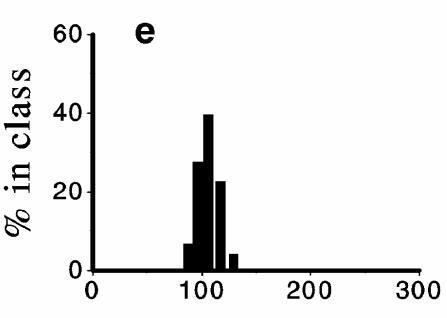

Diameter(nm)

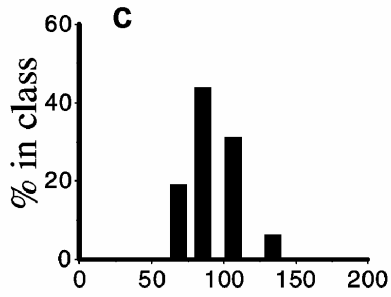

Diameter(nm)

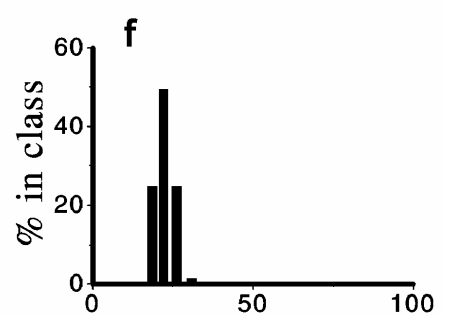

Diameter(nm)

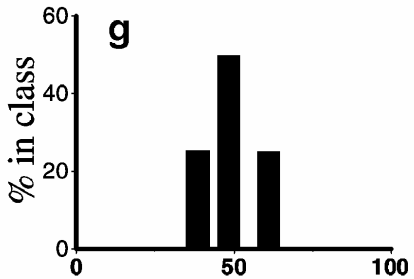

Diameter (nm)

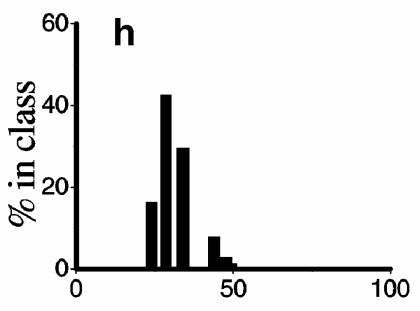

Diameter $(\mathrm{nm})$

Figure 1. Size distribution of the particles obtained by different approaches. (a) without stearic acid. (b-d) $1 \mathrm{wt} \%, 3 \mathrm{wt} \%, 5 \mathrm{wt} \%$ of stearic acid, respectively. (e-f) stearic acid (3 wt\%). (g) tetradecanoic acid (6 wt\%). (h) hexadecanoic acid (4 wt\%). a-d were performed by approach (I), with (e) approach (II) and $\mathbf{f}-\mathbf{h}$ approach (III).

was obvious. Comparing figure $2 \mathrm{c}$ with $2 \mathrm{~b}$, we conclude that approach (II) resulted in similar size (70 \pm $2.2 \mathrm{~nm}$ ) but with better dispersion. When approach (III) was used, the average diameter of the particles decreased greatly to $25 \pm 1.3 \mathrm{~nm}$ (figure 2d), $20 \pm 1.9 \mathrm{~nm}$ (figure 2e) and $16 \pm 1.3 \mathrm{~nm}$ (figure 2f), which corresponded to the optimal addition of tetradecanoic acid, hexadecanoic acid and stearic acid, respectively. The illustrated approach (III) was more suitable for preparation of smaller particles. The same results were obtained by reproducible experiments.

The above result was consistent with that obtained by DLLS. From figures $2 d-f$, it could be seen that the particle diameters decreased with increase of the chain length of the organic acid, which could also be seen in figure $1 \mathrm{~g}, \mathrm{~h}$ and $\mathrm{f}$. Since longer chain could cover the surface of the particles more effectively inhibiting the growth of the crystals, the optimal amount of the longer chain organic acid was less than the shorter.

The difference between the above measurements was that the diameters determined by DLLS were larger, as they represented the hydraulic diameter of the particle. ${ }^{15}$

Figure 3 showed the XRD patterns of particles prepared by approach (III) with $3 \mathrm{wt} \%$ stearic acid. All the diffraction peaks could be indexed with reference to the unit cell of the barite structure (JCPDS card: 24-1035). The diffraction peaks of (101), (111), (021), (121), (002) and (212) were the characteristic peaks of orthorhombic $\mathrm{BaSO}_{4}$ crystal, demonstrating that the product accurately $\mathrm{BaSO}_{4}$.

For XRD data of nanoparticles, the use of DebyeScherrer equation is the normal procedure to estimate particle size. Here the diameters of the $\mathrm{BaSO}_{4}$ obtained were calculated as follows: 

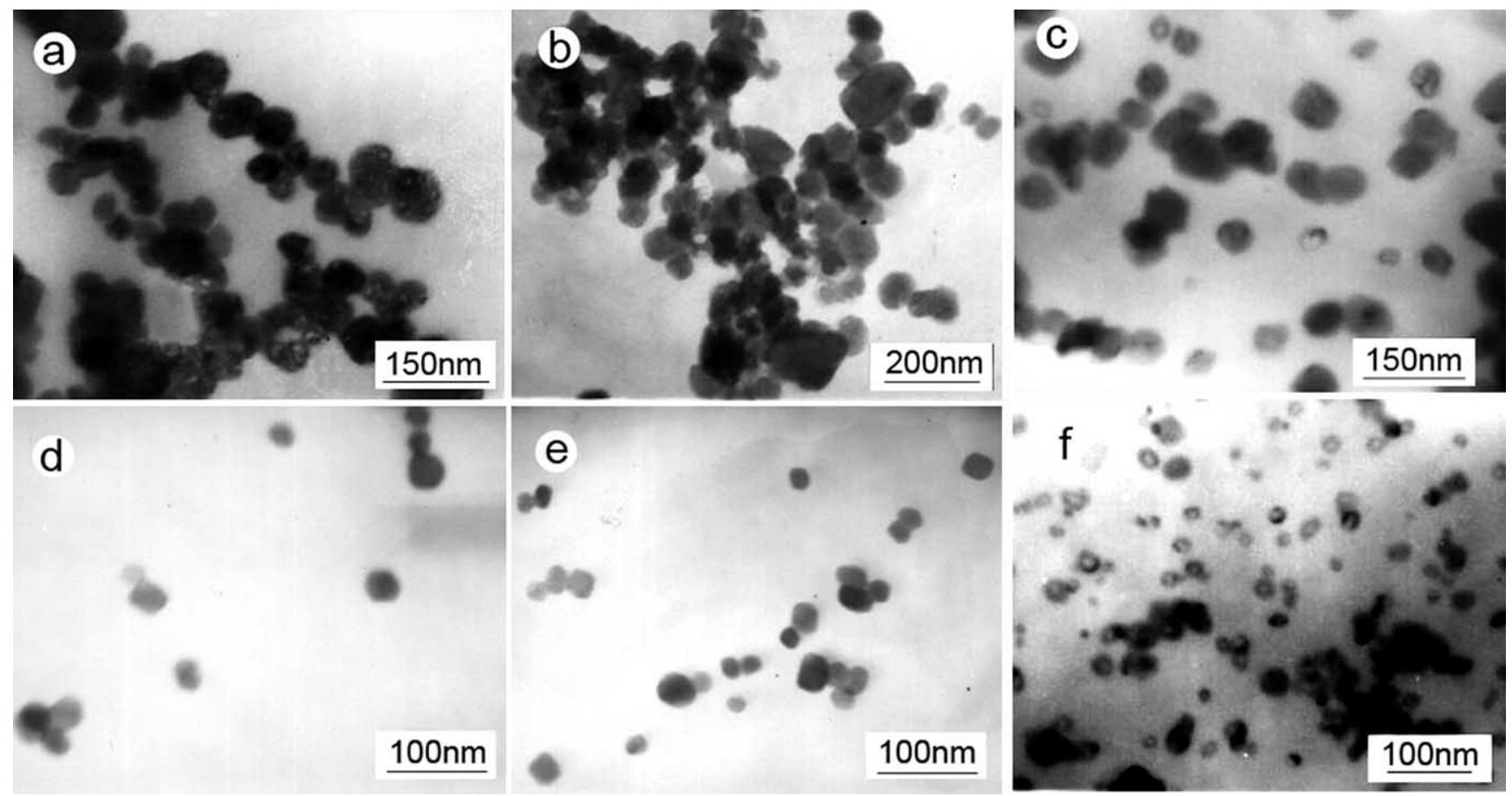

Figure 2. TEM images of the particles obtained in different approaches. (a) without organic acid (b) 3 wt\% stearic acid (c) $3 \mathrm{wt} \%$ stearic acid (d) $6 \mathrm{wt} \%$ tetradecanoic acid (e) $4 \mathrm{wt} \%$ hexadecanoic acid (f) $3 \mathrm{wt} \%$ stearic acid b was prepared by approach (I), with c approach (II) and d-f approach (III).

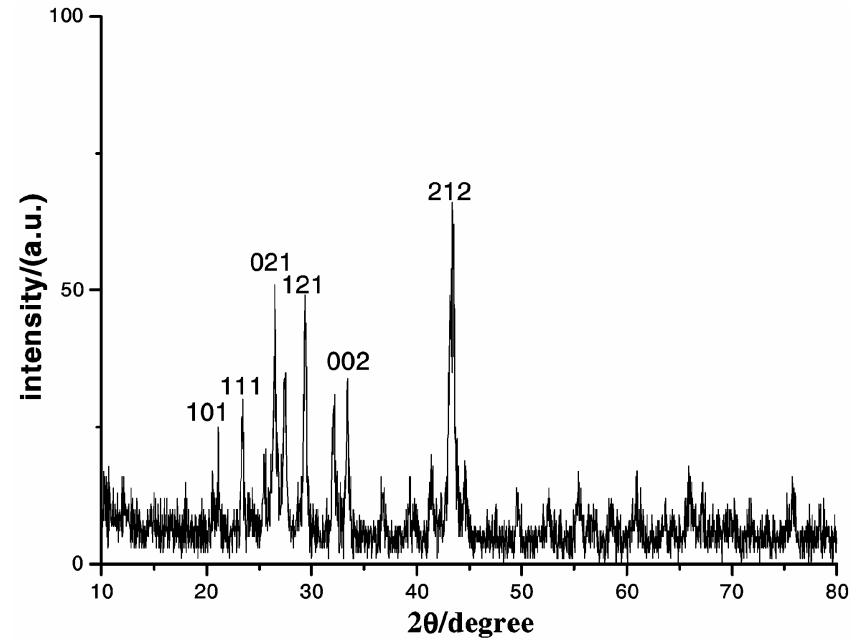

Figure 3. XRD patterns of barium sulphate nanoparticles (obtained by approach (III) with $3 \mathrm{wt} \%$ stearic acid).

$$
D=K \lambda / \beta \cos \theta
$$

where $D, K, \lambda, \beta, \theta$ are the average diameter, the shape factor, the X-ray wavelength, the width of the peak (full width at half maximum) and the Bragg's diffraction angle, respectively. The crystallite sizes of the sample are estimated from the line width of the (212) XRD peaks.
In our system, $K$ equals $0.89, \lambda=1.5418 \AA$. The value of $2 \theta$ is 43.44 as shown in the figure. $\beta$ is 0.62 , as calculated using the obtained data. The diameter of $\mathrm{BaSO}_{4}(\mathrm{D})$ can then be estimated as $13.6 \mathrm{~nm}$ according to the Scherrer equation. The result is in good agreement with TEM analysis $(16 \mathrm{~nm})$.

Figure 4 shows the FT-IR spectra of $\mathrm{BaSO}_{4}$ nanoparticles modified by different organic acids. The bands centred at $1073-1192 \mathrm{~cm}^{-1}$ and the shoulder at $982 \mathrm{~cm}^{-1}$ were the symmetrical vibration of $\mathrm{SO}_{4}^{2-}$. The peaks at 610 and $638 \mathrm{~cm}^{-1}$ corresponded to the out-of-plane bending vibration of the $\mathrm{SO}_{4}^{2-}$. The interaction between carboxylate ions and $\mathrm{BaSO}_{4}$ made the broad peaks at $1073-1192 \mathrm{~cm}^{-1}$ different from the sharp peaks at $1080-1130 \mathrm{~cm}^{-1}$ of pure $\mathrm{BaSO}_{4}$. It could also be observed that the intensity of peaks decreased in the order of $a, b, c$, arising from the different interaction between different organic carboxylate ions and barium sulphate. The peaks at 2851 and $2920 \mathrm{~cm}^{-1}$ could be assigned to the symmetric and asymmetric vibrations of $-\mathrm{CH}_{2}-$ and $-\mathrm{CH}_{3}$ groups. The peaks at 1436 and $1402 \mathrm{~cm}^{-1}$ were ascribed to the scissoring of $-\mathrm{CH}_{2}-$ or the symmetric deformation of the $-\mathrm{CH}_{3}$ group. All bands above were attributed to the nonpolar part in organic acid, which indicated the existence of long-chain aliphatic groups in the 
sample. The strong peak at $1704 \mathrm{~cm}^{-1}\left(v_{\mathrm{c}=0}\right)$ of organic acid disappeared, while the new peak at $1549 \mathrm{~cm}^{-1}$ was observed, which demonstrated that the organic acid was present in the form of carboxylate ions rather than free organic acid.

The FT-IR spectra showed that the particles contained organic acid and there was no corresponding peaks in XRD patterns. This may be because the organic acid was absorbed on the surface of $\mathrm{BaSO}_{4}$ rather than entering the $\mathrm{BaSO}_{4}$ crystal to form composite.

TG analysis of $\mathrm{BaSO}_{4}$ modified by stearic acid and pure stearic acid is shown in figure 5. Curve 5a showed that stearic acid decomposed from 200 to $450^{\circ}$. However, $\mathrm{BaSO}_{4}$ modified by the stearic acid began to lose at $350^{\circ}$ and the main was from $500^{\circ}$ to

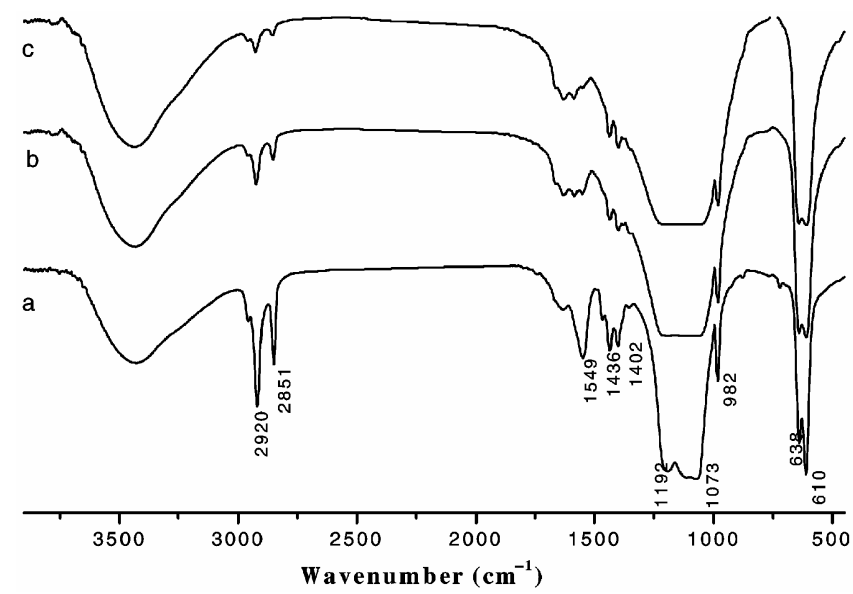

Figure 4. FT-IR spectra of particles modified by different organic acid in approach (III) (a) $3 \mathrm{wt} \%$ stearic acid, (b) $4 \mathrm{wt} \%$ hexadecanoic acid, (c) $6 \mathrm{wt} \%$ tetradecanoic acid.

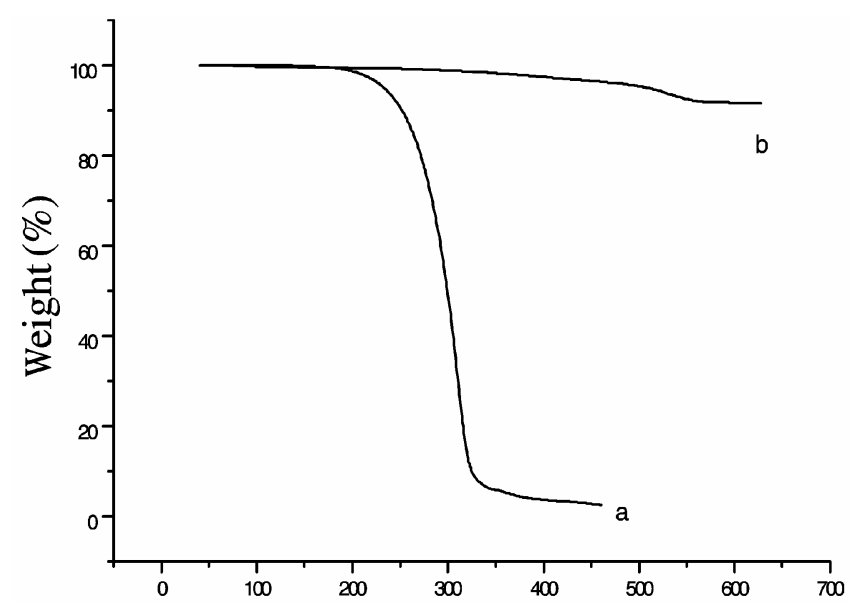

Figure 5. TG Curves for the pure stearic acid (a) and $\mathrm{BaSO}_{4}$ modified by $3 \mathrm{wt} \%$ stearic acid using approach (III) (b). $550^{\circ}$. The main loss was about $8 \%$ which was suggested by the curve $5 \mathrm{~b}$. The decomposition temperature of stearic acid modifying $\mathrm{BaSO}_{4}$ was higher than pure stearic acid, resulting from the interaction between $\mathrm{R}-\mathrm{COO}^{-}$and $\mathrm{Ba}^{2+}$.

\section{Formation mechanism of $\mathrm{BaSO}_{4}$ nanoparticles}

Approach (I): The reason that the average diameter of $\mathrm{BaSO}_{4}$ particles in the presence of organic acid was smaller than that obtained without organic acid was that when the organic acid was added into the reaction system, the growth of $\mathrm{BaSO}_{4}$ was prevented due to the steric hindrance of organic acid on the surface of $\mathrm{BaSO}_{4}$ particle. But the steric hindrance was so weak that the difference was negligible.

Approach (II): The average diameter of $\mathrm{BaSO}_{4}$ obtained in this system was about $70 \mathrm{~nm}$, which was larger than that obtained in approach (III). It might be relative to the rate of release of the $\mathrm{RCOO}^{-}$. The possible reactions were as follows:

$$
\begin{aligned}
& \mathrm{RCOOH}+\mathrm{NH}_{3} \cdot \mathrm{H}_{2} \mathrm{O} \rightarrow \mathrm{RCOO}^{-}+\mathrm{NH}_{4}^{+}+\mathrm{H}_{2} \mathrm{O} \\
& \mathrm{RCOO}^{-}+\mathrm{Ba}^{2+} \rightarrow(\mathrm{RCOO})_{2} \mathrm{Ba} \downarrow
\end{aligned}
$$

When ammonia was first added into solution $\mathrm{B}$, reaction took place immediately. Because $\mathrm{NH}_{3} \cdot \mathrm{H}_{2} \mathrm{O}$ was surplus, $\mathrm{RCOO}^{-}$was fully released. But due to the presence of a large number of $\mathrm{Ba}^{2+}$ in solution $\mathrm{B}$, reaction took place subsequently. As a result, the $\mathrm{RCOO}^{-}$was decreased and there was not enough $\mathrm{RCOO}^{-}$serving as modifier to prevent aggregation, leading to larger size.

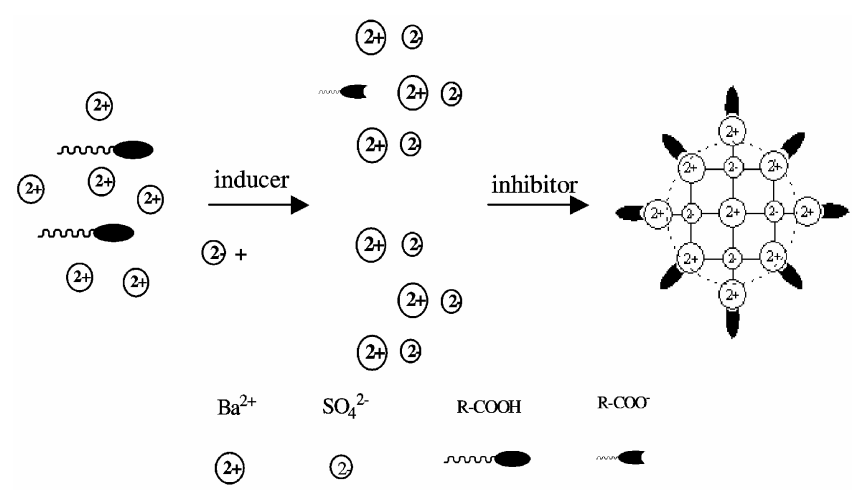

Figure 6. The possible mechanism of the $\mathrm{BaSO}_{4}$ nanoparticles modified by organic acid. 
But when solution A containing ammonia was dropped into solution $\mathrm{B}$, the release of $\mathrm{RCOO}^{-}$was relatively slow. They could be absorbed on the surface of $\mathrm{BaSO}_{4}$ to decrease the size.

Approach (III): When solution A with the $\mathrm{pH}=8$ 9 by adding ammonia (added drop-wise) into solution $\mathrm{B}$, the reaction process was:

$$
\begin{aligned}
& \mathrm{SO}_{4}^{2-}+\mathrm{Ba}^{2+} \rightarrow \mathrm{BaSO}_{4} \downarrow \\
& \mathrm{RCOOH}+\mathrm{NH}_{3} \cdot \mathrm{H}_{2} \mathrm{O} \rightarrow \mathrm{RCOO}^{-}+\mathrm{NH}_{4}^{+}+\mathrm{H}_{2} \mathrm{O} .
\end{aligned}
$$

In this process, reaction could be ignored because $\mathrm{BaSO}_{4}$ was easier to settle down than $(\mathrm{RCOO})_{2} \mathrm{Ba}$.

$\mathrm{Ba}^{2+}$ was relatively surplus because $\mathrm{SO}_{4}^{2-}$ was dropped into $\mathrm{Ba}^{2+}$ in the process. Initially, a small amount of $\mathrm{SO}_{4}^{2-}$ was dropped into the system. $\mathrm{RCOO}^{-}$acted as an inducer to attract $\mathrm{Ba}^{2+}$ via electrostatic forces. With the addition of $\mathrm{SO}_{4}^{2-}, \mathrm{BaSO}_{4}$ crystals formed gradually. $\mathrm{RCOO}^{-}$still covered the surface of the $\mathrm{BaSO}_{4}$ crystals, resulting in the inhibition of further growth of $\mathrm{BaSO}_{4}$ nanoparticles, which was the reason for smaller size and uniform distribution of particles. During the process, organic acid played two roles: inducer and inhibitor. The average diameter of $\mathrm{BaSO}_{4}$ nanoparticles decreased in the order of addition of tetradecanoic acid, hexadecanoic acid and stearic acid, which was possibly related to the chain length of organic acid. The longer the chain length, the greater the steric hindrance.

\section{Conclusions}

The application of materials composed of nanoparticles was inhibited by the trend to aggregate. Here we succeeded in preparing $\mathrm{BaSO}_{4}$ nanoparticles with good dispersion using a facile method under mild conditions. $\mathrm{BaSO}_{4}$ nanoparticles modified by tetra- decanoic acid, hexadecanoic acid and stearic acid were prepared. The diameter of $\mathrm{BaSO}_{4}$ reached minimum when ammonia was first added into $\mathrm{Na}_{2} \mathrm{SO}_{4}$ ethanol-water solution, then $\mathrm{Na}_{2} \mathrm{SO}_{4}$-ethanol-water solution was added drop-wise into $\mathrm{BaCl}_{2}$-ethanolwater solution containing organic acid. The average diameter of barium sulphate was about 25, 20 and $16 \mathrm{~nm}$ obtained in the reaction system containing tetradecanoic acid, hexadecanoic acid and stearic acid respectively. XRD indicated that barium sulphate particles were all orthorhombic. This method might be suitable for preparation of other materials as well and could have future application in the industry.

\section{Acknowledgement}

This work was supported by the National Science Foundation of China.

\section{References}

1. Lee J K and Choi S M 2003 B. Kor. Chem. Soc. 2432

2. Qi L M, Cölfen H and Antonietti M 2000 Chem. Mater. 122392

3. Rautaray D et al 2002 Cryst. Growth. Des. 2197

4. Mostafa A and Sayed E 2001 Chem. Res. 34257

5. Qi L M, Cölfen H and Antonietti M 2000 Angew. Chem. Int. Ed. 39604

6. Jones F et al 2004 J. Cryst. Growth 270593

7. Yu J G, Liu S W and Cheng B 2005 J. Cryst. Growth 275572

8. Jones F et al 2003 J. Cryst. Growth 249584

9. Lu L H et al 2000 Colloid Surf. A175 161

10. Hopwood J D and Mann S 1997 Chem. Mater. 91819

11. Li M and Mann S 2000 Langmuir 167088

12. Gan L M et al 1995 Mater. Chem. Phys. 4094

13. Wang K, Wu J S and Ye L 2003 Compos. Part AAPPL S 341199

14. Sui X M, Chu Y, Xing S X and Liu C Z 2004 Mater Lett. $\mathbf{5 8} 1255$

15. Sonntag H and Strenge K 1987 Coagulation kinetics and structure formation (M. Berlin: VEB 64-72) 